\title{
Experimental and Numerical Study on Fracture Characteristics of Interface between In Situ Engineered Cementitious Composites and Steel Deck
}

\author{
Weiwei Han, Shuyin Wu $(\mathbb{D}$, Xue Gao, Xinyao Zong, and Jingsong Shan \\ Shandong Key Laboratory of Civil Engineering Disaster Prevention and Mitigation, \\ Shandong University of Science and Technology, Qingdao 266590, China \\ Correspondence should be addressed to Shuyin Wu; wushuyin@sdust.edu.cn
}

Received 11 December 2020; Revised 12 January 2021; Accepted 28 January 2021; Published 8 February 2021

Academic Editor: Shuaicheng Guo

Copyright (c) 2021 Weiwei Han et al. This is an open access article distributed under the Creative Commons Attribution License, which permits unrestricted use, distribution, and reproduction in any medium, provided the original work is properly cited.

In this study, engineered cementitious composite (ECC) is used as the pavement of orthotropic steel deck bridge and an epoxy adhesive is used to achieve wet-bonding between the steel deck and cast-in-place ECC. To investigate the fracture properties of bimaterial interface, the double cantilever beam (DCB) and 4-point end notched flexure (4ENF) specimens were used to obtain the fracture toughness, and virtual crack closure technology (VCCT) was used to calculate the energy release rates. A mixed fracture criterion was also established based on the blister test in this study. In addition, for the phenomena of water accumulation in the interface cracks, the hydrodynamic pressure under load was evaluated with a two-way fluid-solid coupling model and the propagation mechanism of cracks at the water-bearing interface was explored. The results showed that the energy release rates at the crack front showed obvious nonuniform distribution characteristics. The blister test indicated that a mixed fracture was in good agreement with the linear fracture criterion. The fracture effect produced by the hydrodynamic pressure of the interfacial water-bearing crack was far less than the fracture toughness of the interface, which indicated that the hydrodynamic pressure could hardly destroy the interface at one time but might cause the erosion fatigue damage of the interface.

\section{Introduction}

As a protective layer of a bridge deck, a deck pavement plays an important role in the service performance of the whole bridge. The small stiffness and local support of the deck are easy to cause distress such as cracking, jostle, and upheaval in the widely used asphalt pavement [1]. Since the 1990s, some scholars have tried to use a cementitious pavement to improve the stiffness of a steel bridge deck and its stress state [2]. In this study, engineered cementitious composite (ECC), a typical kind of high ductility cementitious composites (HDCC), is used as the pavement of an orthotropic steel deck bridge. The stiffness of a bridge deck system can be improved by using ECC without increasing the thickness and weight of the pavement because of the lightweight and high strength of ECC. In terms of interface connection between the cementitious pavement and steel deck, wet- bonding technology has evolved as a new bonding technique [3-7] and is used in this study to achieve an effective connection between the steel deck and cast-in-place ECC. Wet-bonding technology is proposed to distinguish from dry-bonding technology. Dry-bonding technology is used for connection between hardened concrete and existing structure, whereas wet-bonding technology is developed to connect existing structure and cast-in-place concrete. The pavement structure for orthotropic steel deck bridges used in this study is shown in Figure 1. The pavement layer from bottom to top is epoxy adhesive, ECC, bond layer, and asphalt wearing layer (optional).

It should be noted that the interface of the pavement structure is a typical the bimaterial interface, which means the properties of the materials on both sides of the interface are different. Meanwhile, there are microdefects in the interface, which will cause stress concentration near the 


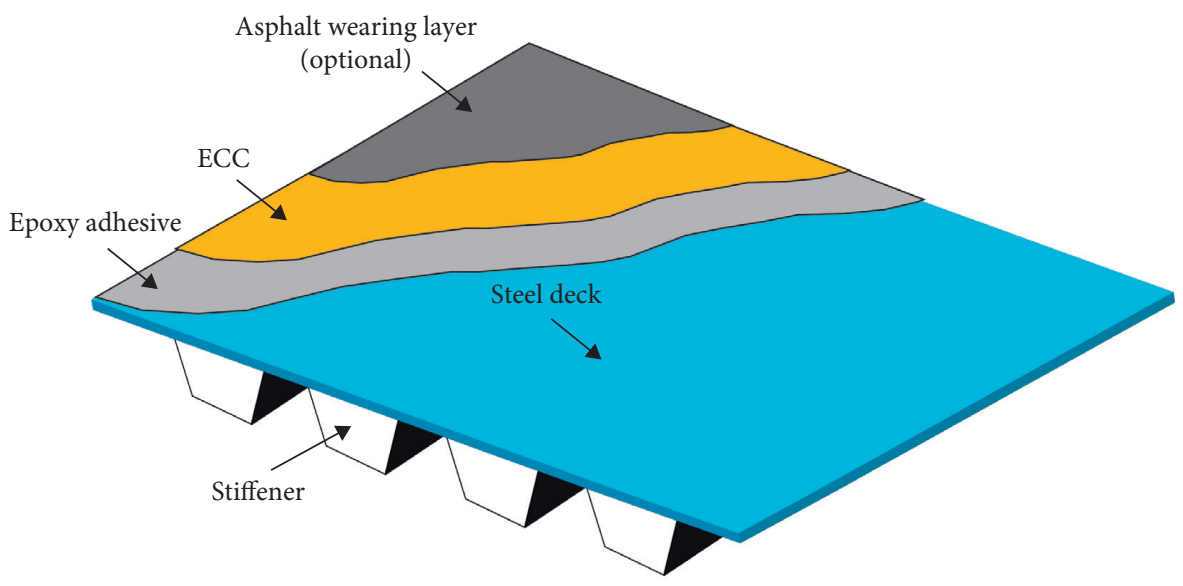

Figure 1: Pavement structure for orthotropic steel deck bridge.

defects. Due to the mismatch of material properties on the bimaterial interface, the stress follows a $\log (r)$ distribution and is totally different from that of the homogeneous materials. The smaller the distance from the crack tip is, the higher the oscillation frequency is, as shown in Figure 2. Crack propagation may lead to the failure of the whole structure. Therefore, the reliability of the whole structure depends to a great extent on the fracture characteristics of the interface.

Because of the existence of a singular stress field, the failure of the bimaterial interface should not be evaluated only by strength parameters (such as stress and strain) but must be evaluated by parameters used to describe the singularity, and this belongs to the field of fracture mechanics. At present, more attention has been paid to the fracture properties of the bimaterial interface and a series of experiments and theoretical studies have been carried out. There are three basic fracture modes: opening mode (Mode I), sliding mode (Mode II), and antiplane shear mode (Mode III). Among them, Mode III rarely appears in the actual structure, so it is not considered in this study. The failure criterion of mixed fracture is usually established based on the combination of Mode I and Mode II fracture. Energy release rate $(G)$, stress intensity factor $(K)$, and $J$-integral $(J)$ are generally adopted to evaluate the fracture properties. Williams [9] used the classical beam theory to give an expression for the energy release rate at the crack tip. Based on the classical beam theory, Suo [10] studied the delamination problem of orthotropic materials and gave an analytical expression of the energy release rate expressed by a single real scalar. Wang and Qiao [11] considered the effect of shear deformation and obtained the analytical solution of the energy release rate and stress intensity factor of the interface crack of the double-layer bonded plate under normal load. Qiao and Wang [12] proposed a flexible node model to analyze the crack tip deformation. In the experimental study of bonded structure fracture toughness, Ripling et al. [13] tested the critical energy release rate of the bond interface using DCB specimens. Wilkins et al. [14] used a DCB to study the interlaminar peel fracture toughness of composites. Yang et al. [15] used the end notched flexure (ENF) to

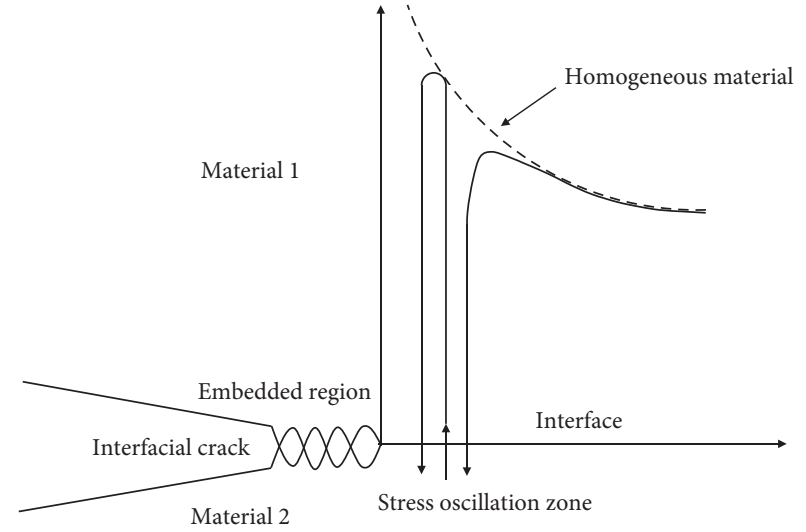

FIgURE 2: Crack tip stress and opening displacement of interface crack [8].

obtain the shear toughness of the bonded interface. Martin and Davidson [16] further improved the ENF to a 4-point end notched flexure (4ENF). Hwu et al. [17] applied four different notched beam specimens (DCB, ENF, CLS (Cracked Lap Shear), and improved ENF) to determine the mixed fracture toughness of the bond interface. Rikards et al. [18] used a clamp with variable loading angle to test the fracture of polymer plates and obtained different energy release rates GI and GII. In terms of the establishment of fracture criterion, Whitcomb [19] believed that the interface cracking is mainly determined by the Mode I energy release rate. Gillepie et al. [20] believed that the interface cracking is mainly played by the Mode II energy release rate, and the effect of Mode I is of little significance. Wu and Rcuter [21] thought that crack propagation is mainly caused by joint action; that is, when the total energy release rate of Modes I and II exceeds the critical value, the crack expands. Later, many scholars standardized the critical energy release rate and proposed the linear fracture criterion, which is also the most widely used criterion. The linear criterion is generalized to obtain the power rate criterion [22], the index criterion [23], and so on.

In addition to the experiments and theoretical studies, many scholars have proposed numerical methods to 
investigate fracture properties, including finite element method, boundary element method, finite difference method, and meshless method, among which finite element method is the most widely used. Virtual crack closure technology (VCCT) is the most typical numerical method based on the finite element method. Rybicki and Kannien [24] first proposed a virtual crack closure method for twodimensional crack problems in 1977 and used it to calculate the strain energy release rate. Shivakumar et al. [25] applied the virtual crack closure method to the three-dimensional crack problem. VCCT is widely used to calculate the energy release rate due to its advantages of a simple solution, high accuracy, low requirement for mesh size, and no special treatment of crack tip.

This study aims to investigate the feasibility of wetbonding technology between the steel deck and cast-in-place ECC from the perspective of fracture characteristics, so as to promote the application of wet-bonding technology in orthotropic steel bridge deck pavement. In this study, DCB and $4 \mathrm{ENF}$ specimens were used to measure the fracture toughness, and VCCT was used to calculate the energy release rate with ANSYS workbench. The blister test is an evaluation method of fracture characteristics under complex loading conditions, which comprehensively reflects the fracture characteristics of the interface. Based on the blister test, a mixed fracture criterion was established in this study. In addition, the pavement material is not completely impervious to water and fatigue cracks may also provide access for water to enter the interior, which may lead to the phenomenon of water accumulation in the interface cracks during the service process. The hydrodynamic pressure generated under load at the interfacial crack is the most disadvantageous factor affecting the propagation of the interfacial crack. Therefore, a two-way fluid-solid coupling model was established with ANSYS workbench in this study to analyze the dynamic water pressure at the interface under load and to explore the propagation mechanism of cracks at the water-bearing interface.

\section{Materials and Experiments}

2.1. Raw Materials. ECC was prepared with cement, fly ash, quartz sand, polyvinyl alcohol (PVA) fiber, water, and water reducer. The properties of the raw materials are listed in Tables 1-3. The mix proportions of ECC are shown in Table 4. The binder used in this study was a two-component epoxy adhesive, which consisted of part A, an epoxy resin, and part B, a hardener [26]. The proportion of components $\mathrm{A}$ and $\mathrm{B}$ was $2: 1$ by weight. The properties of the adhesive are listed in Table 5. The steel plate was sandblasted to remove the rust and sprayed with an epoxy zinc-rich paint.

2.2. Preparation Procedure for ECC. The mixing procedure for ECC was as follows:

(1) Cement, fly ash, and silica sand were added into a blender and mixed at $100 \mathrm{rpm}$ for $3 \mathrm{~min}$.
(2) Water and water reducer which was previously dissolved in the water were added and mixed at $100 \mathrm{rpm}$ for $1 \mathrm{~min}$ and then $400 \mathrm{rpm}$ for $4 \mathrm{~min}$.

(3) Fibers were added slowly and manually along the stirring direction and mixed at $400 \mathrm{rpm}$ for $10 \mathrm{~min}$.

2.3. Fracture Toughness Test. The combination of laboratory test and numerical analysis was used to study the fracture properties of steel deck/ECC interface. The bending stiffness of ECC and steel plate in the composite structure of steel plate and ECC should be equal. According to this, the thickness of the steel plate was $6.5 \mathrm{~mm}$ and the thickness of ECC was $15.5 \mathrm{~mm}$. The preparation of specimens for fracture test is as follows:

(1) The steel plates were coated with epoxy binder and put into the molds. Epoxy binder was cured at room temperature $\left(20^{\circ} \mathrm{C}\right)$ for 30 minutes, and then, ECC was cast in the molds.

(2) The specimens were demolded after 24 hours and then kept in a standard curing box at a relative humidity of $(95 \pm 5) \%$ and a temperature of $(20 \pm 2)^{\circ}$ $\mathrm{C}$ for 28 days. Precracking was obtained by prepositioning a thin layer of tape between the steel plates and ECC. Four parallel specimens were used in each type of test.

Mode I fracture toughness was measured with DCB specimens, as shown in Figure 3. The specimens had a length of $0.400 \mathrm{~m}$, a width of $0.070 \mathrm{~m}$, and an initial crack length of $0.150 \mathrm{~m}$. The tests were performed with a universal testing machine. The test process adopted the displacement control loading mode, and the loading rate was $0.5 \mathrm{~mm} / \mathrm{min}$. The load and displacement were automatically collected by the built-in sensors of the testing machine.

The fracture toughness of Mode II was tested with $4 \mathrm{ENF}$ specimens. The specimens had a length of $0.400 \mathrm{~m}$, a width of $0.070 \mathrm{~m}$, and an initial crack length of $0.200 \mathrm{~m}$. The loading rate was $0.5 \mathrm{~mm} / \mathrm{min}$. The loading device is shown in Figure 4.

2.4. Blister Test. Blister test was proposed by Dannenberg in 1961 and used to quantify the adhesion between the film and the matrix. Nowadays, it has been widely used to evaluate the interfacial bonding properties [27]. The failure in the blister test is a mixed mode fracture and a fracture criterion of the steel-ECC interface can be established based on the blister test. The specimens used in this study had a total length of $0.400 \mathrm{~m}$, a width of $0.070 \mathrm{~m}$, and a notch length of $0.100 \mathrm{~m}$. The thickness of ECC was $10 \mathrm{~cm}$, and the thickness of the steel plates was $12 \mathrm{~mm}$. The bottom of the steel plates was completely fixed. The loading rate was $0.5 \mathrm{~mm} / \mathrm{min}$. A three-dimensional finite element model of the blister specimen was established according to the actual size of the specimen and the energy release rate was calculated based on VCCT. The blister test and the finite element model are shown in Figure 5. 
Table 1: Chemical composition of Portland cement and fly ash.

\begin{tabular}{lcccccccccc}
\hline \multirow{2}{*}{ Material } & \multicolumn{1}{c}{ Chemical component (by weight, \%) } \\
& $\mathrm{SiO}_{2}$ & $\mathrm{CaO}$ & $\mathrm{Al}_{2} \mathrm{O}_{3}$ & $\mathrm{Fe}_{2} \mathrm{O}_{3}$ & $\mathrm{SO}_{3}$ & $\mathrm{P}_{2} \mathrm{O}_{5}$ & $\mathrm{~K}_{2} \mathrm{O}$ & $\mathrm{Na}_{2} \mathrm{O}$ & $\mathrm{TiO}_{2}$ & $\mathrm{MgO}$ \\
\hline Cement & 21.26 & 57.82 & 7.67 & 2.88 & 4.04 & 5.26 & 0.78 & - & 0.21 & - \\
Fly ash & 56.18 & 2.82 & 31.46 & 3.85 & 0.69 & 0.91 & - & 1.32 & - \\
\hline
\end{tabular}

TABle 2: Physical and mechanical properties of PAV fiber.

\begin{tabular}{lccccc}
\hline Diameter $(\mu \mathrm{m})$ & Length $(\mathrm{mm})$ & Elongation $(\%)$ & Density $\left(\mathrm{g} / \mathrm{cm}^{3}\right)$ & Elastic modulus $(\mathrm{GPa})$ & Tensile strength $(\mathrm{MPa})$ \\
\hline 35 & 12 & 7.3 & 1.3 & 31.3 & 1287 \\
\hline
\end{tabular}

Table 3: Properties of quartz sand.

\begin{tabular}{lccc}
\hline $\mathrm{SiO}_{2}$ content $(\%)$ & Melting point $\left({ }^{\circ} \mathrm{C}\right)$ & Density $\left(\mathrm{g} / \mathrm{m}^{3}\right)$ & Mohr's hardness \\
\hline 98.7 & 1760 & 2.66 & 7 \\
\hline
\end{tabular}

TABle 4: Mix proportions $\left(\mathrm{kg} / \mathrm{m}^{3}\right)$.

\begin{tabular}{lccccc}
\hline Cement & Fly ash & Water & Sand & Fiber & Water reducer \\
\hline 479 & 719 & 359 & 431 & 26 & 9.6 \\
\hline
\end{tabular}

Table 5: Properties of epoxy adhesive.

\begin{tabular}{lcccccc}
\hline Tension & $\begin{array}{c}\text { Strength }(\mathrm{MPa}) \\
\text { Compression }\end{array}$ & Shear & Tension & $\begin{array}{c}\text { Modulus (GPa) } \\
\text { Compression }\end{array}$ & Shear & Elongation rate \\
\hline 25 & 75 & 8.9 & 4.6 & 5.0 & 3.05 & $0.30 \%$ \\
\hline
\end{tabular}
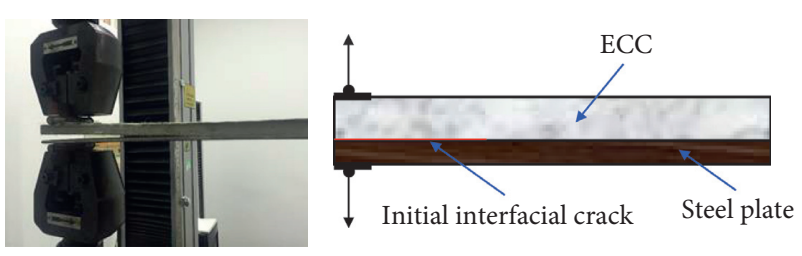

Figure 3: Mode I fracture toughness test.
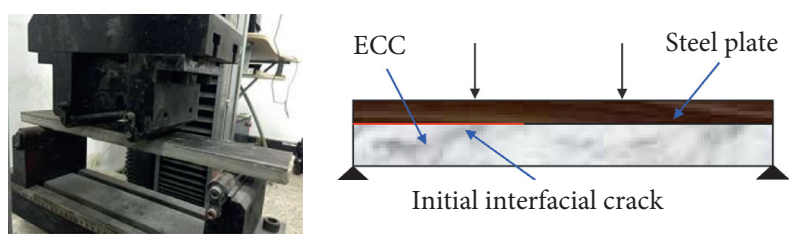

FIgURE 4: Mode II fracture toughness test.

2.5. Interfacial Crack Propagation Mechanism under LoadWater Coupling. The permeation of water and the fatigue cracks that occurred in the service process may lead to the phenomenon of water accumulation in the interfacial cracks. The water in the interfacial cracks will produce strong hydrodynamic pressure under the action of driving load. Hydrodynamic pressure may promote the growth of interfacial cracks, which is very harmful to structural safety. Actually, the hydrodynamic pressure of the interfacial waterbearing cracks belongs to the bidirectional fluid-solid coupling problem. Therefore, a three-dimensional bidirectional fluid-solid coupling model was established to investigate the hydrodynamic pressure. The influence of various factors on the hydrodynamic pressure in the cracks was studied, which provided a basis for the analysis of the influence of hydrodynamic pressure on the interface crack propagation. As shown in Figure 6, assuming that the interfacial crack was completely filled with water, and a semisinusoidal load was applied to the top of the pavement to simulate the driving load. The three-dimensional fluidsolid coupling model is shown in Figure 7. The material parameters of pavement, steel deck, and water are shown in Table 6.

\section{Results and Discussion}

3.1. Mode I Fracture Toughness. A three-dimensional finite element model was established according to the actual size of the DCB specimen, as shown in Figure 8. The contact condition between layers was frictionless at the position of precracking and interface elements were used in other locations with the interface delamination module in the 


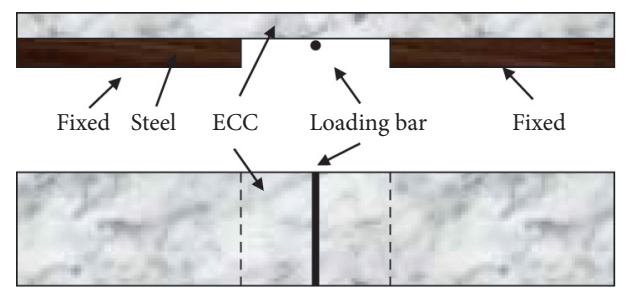

(a)

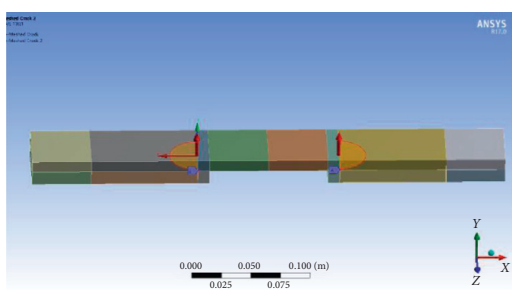

(b)

Figure 5: Blister test. (a) Experimental diagram. (b) Finite element model.
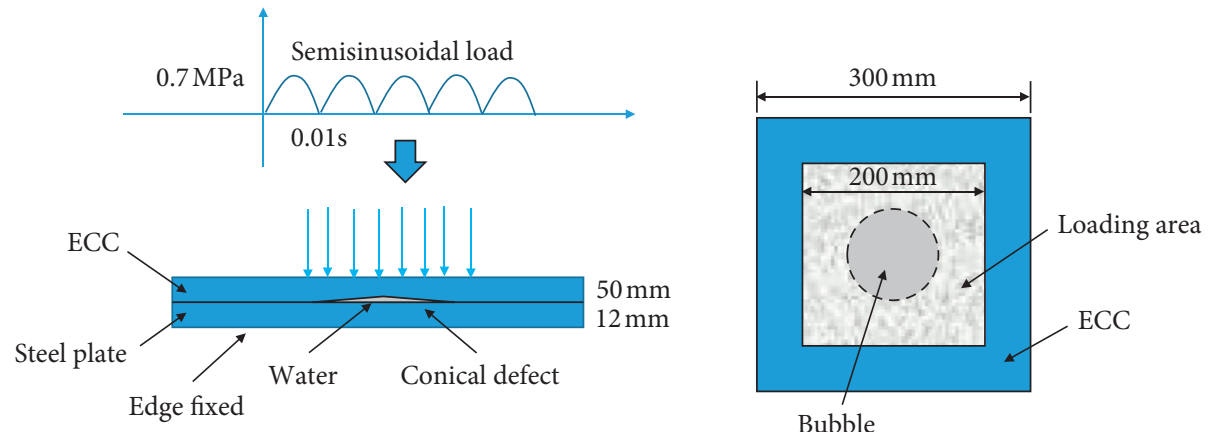

FIgURE 6: Schematic diagram of the computational model.

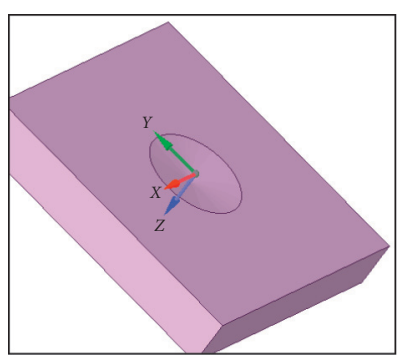

(a)

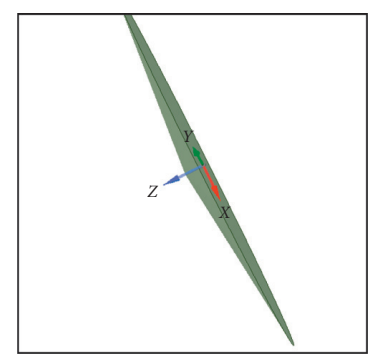

(b)

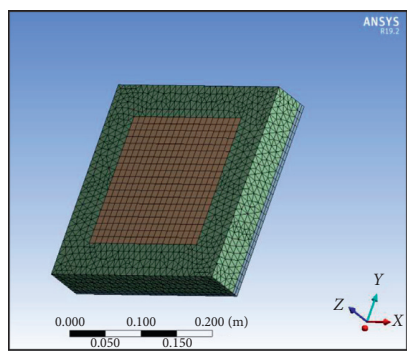

(c)

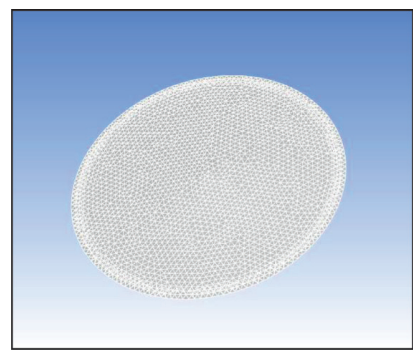

(d)

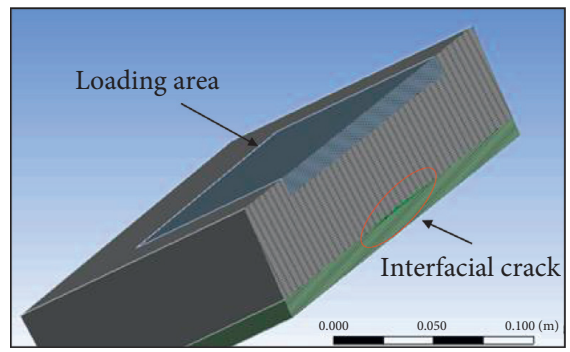

(e)

Figure 7: Three-dimensional fluid-solid coupling analysis model. (a) Pavement. (b) Water at the interface. (c) Mesh of solid. (d) Mesh of fluid. (e) Complete fluid-solid coupling model.

ANSYS workbench. The load and displacement at the same position as the experimental test setup in the model were recorded. Figure 9 shows the typical load-displacement curves of the test results and finite element simulation results.

The energy release rates of parallel specimens were calculated based on VCCT, and the results are shown in Figure 10. It can be found from the figure that the energy release rates at the crack front showed obvious nonuniform distribution characteristics. The uneven distribution of energy at the crack front would lead to the curvilinear propagation of the cracks.

3.2. Mode II Fracture Toughness. A three-dimensional finite element model of 4ENF was established, as shown in Figure 11. Based on VCCT, the energy release rates of 4ENF 
TABLE 6: Main material parameters.

\begin{tabular}{lcc}
\hline Item & Parameter & Value \\
\hline \multirow{2}{*}{ ECC } & Modulus of elasticity $(\mathrm{GPa})$ & 15 \\
& Density $\left(\mathrm{kg} / \mathrm{m}^{3}\right)$ & 2040 \\
Steel & Poisson's ratio & 0.2 \\
& Modulus of elasticity $(\mathrm{GPa})$ & 210 \\
\hline & Density $\left(\mathrm{kg} / \mathrm{m}^{3}\right)$ & 7850 \\
Water & Poisson's ratio & 0.3 \\
& Density $\left(\mathrm{kg} / \mathrm{m}^{3}\right)$ & 998.2 \\
& Dynamic viscosity $(\mathrm{Pa} \cdot \mathrm{s})$ & $1.005 \times 10^{-3}$ \\
\hline
\end{tabular}

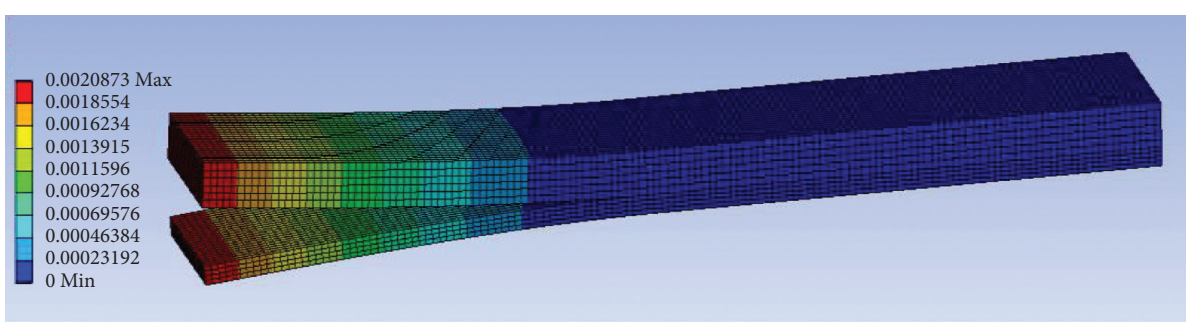

Figure 8: Deformation of DCB specimen.

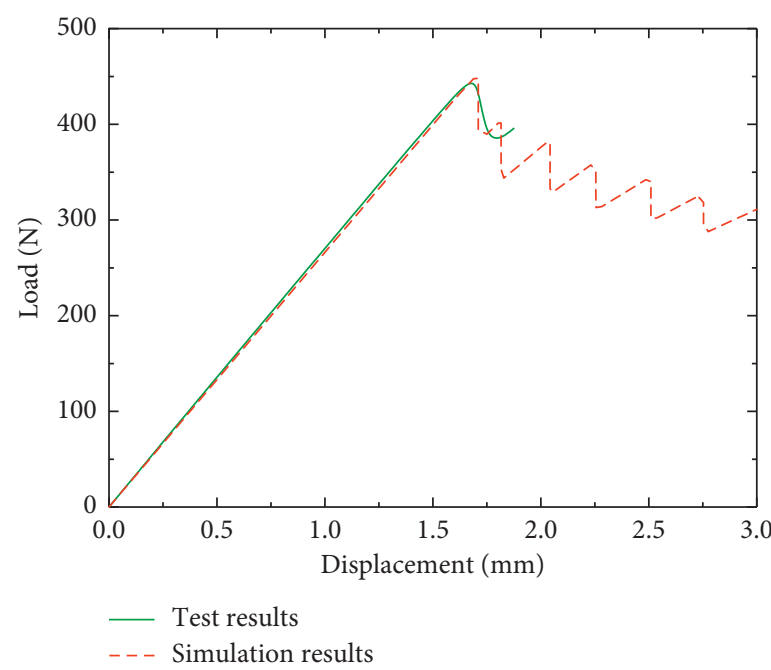

Figure 9: Typical load-displacement curves of experiment and simulation results.

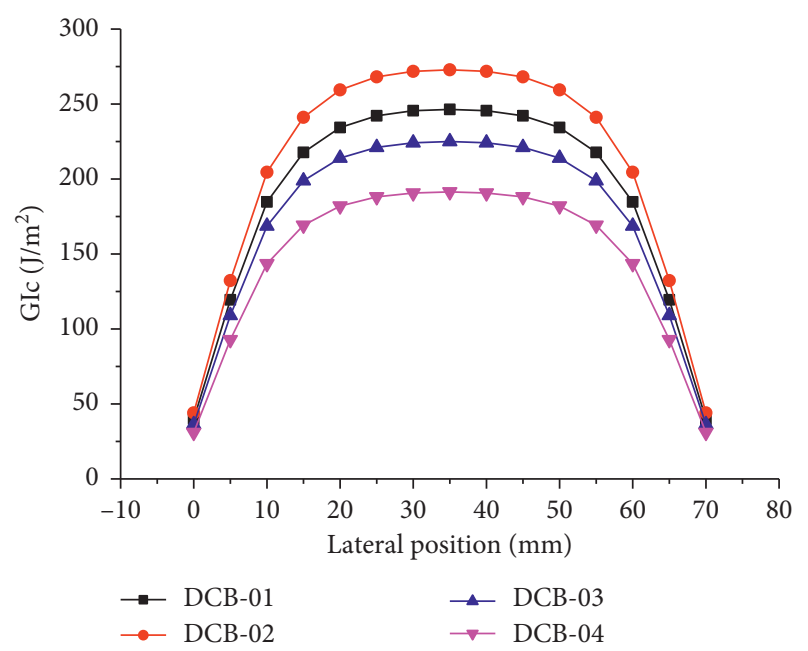

FIgURE 10: Energy release rate distribution at the crack front of DCB. 


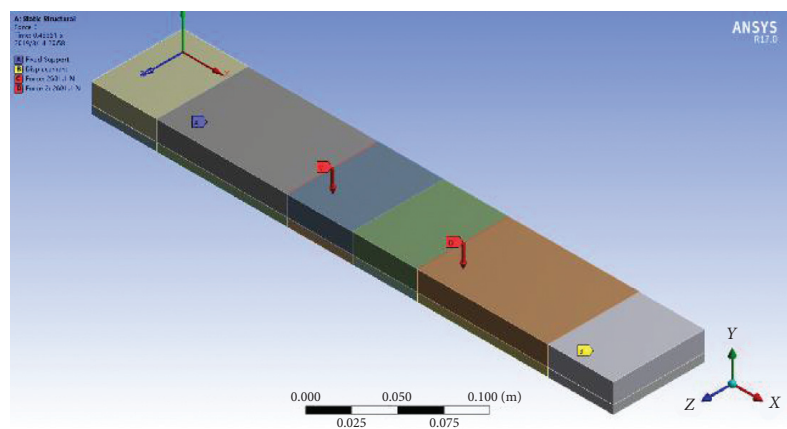

(a)

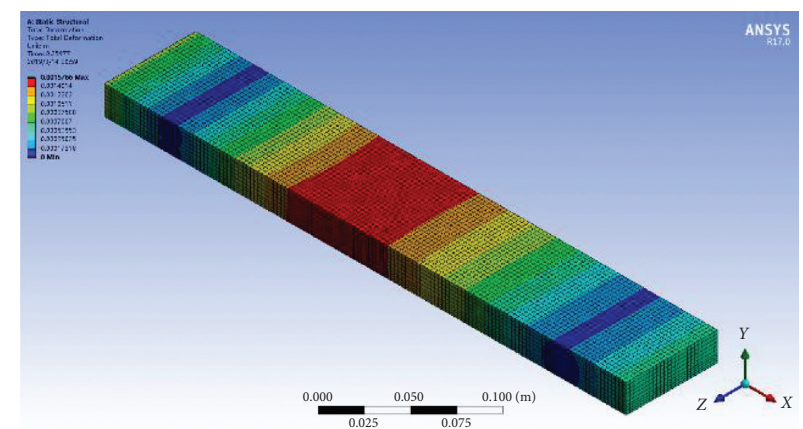

(b)

FIgURE 11: FEM model and simulation result. (a) 4ENF specimen. (b) Total deformation.

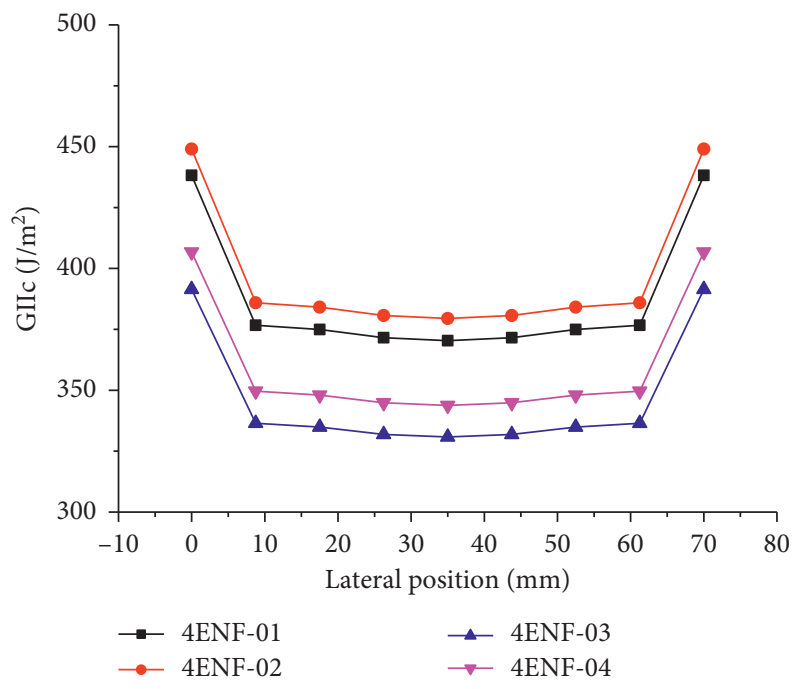

Figure 12: Energy release rates of 4ENF.

TABLE 7: Results of blister test and simulation.

\begin{tabular}{lcccccccc}
\hline Specimen & $P(\mathrm{~N})$ & $G_{\mathrm{I}}\left(\mathrm{J} / \mathrm{m}^{2}\right)$ & $G_{\mathrm{II}}\left(\mathrm{J} / \mathrm{m}^{2}\right)$ & $G_{\mathrm{Ic}}\left(\mathrm{J} / \mathrm{m}^{2}\right)$ & $G_{\mathrm{II} c}\left(\mathrm{~J} / \mathrm{m}^{2}\right)$ & $G_{\mathrm{I}} / G_{\mathrm{Ic}}$ & $G_{\mathrm{II}} / G_{\mathrm{II} c}$ & $G_{\mathrm{I}} / G_{\mathrm{Ic}}+G_{\mathrm{II}} / G_{\mathrm{II} c}$ \\
\hline BT-001 & 3768.8 & 160.06 & 130.39 & 233.938 & 421.365 & 0.684198 & 0.309447 & 0.993645 \\
BT-002 & 4030.6 & 180.05 & 146.95 & 233.938 & 421.365 & 0.769648 & 0.348748 & 1.118396 \\
BT-003 & 3503.6 & 140.23 & 115.85 & 233.938 & 421.365 & 0.599432 & 0.27494 & 0.874372 \\
\hline
\end{tabular}

specimens were calculated, and the results are shown in Figure 12. It can be seen from the figure that the energy release rates at the crack front of $4 \mathrm{ENF}$ specimens also shown obvious nonuniform distribution characteristics. Contrary to the DCB specimens, the energy release rates of $4 \mathrm{ENF}$ specimens are small in the middle and large on both sides.

In addition, the fracture toughness of Mode II is obviously larger than that of Mode I. Therefore, Mode I fracture in the structure is more dangerous and easier to cause brittle fracture under a low-stress condition.
3.3. Blister Test. The fracture parameters obtained by the blister test were compared with those obtained by $\mathrm{DCB}$ and $4 \mathrm{ENF}$ in Table 7 . It is found that $G_{\mathrm{I}} / G_{\mathrm{Ic}}+G_{\mathrm{II}} / G_{\mathrm{II} c}$ was close to 1 , which indicated that the mixed fracture was in good agreement with the linear fracture criterion.

3.4. Hydrodynamic Pressure of Water-Bearing Interfacial Crack. The hydrodynamic pressure of the water-bearing cracks can be obtained after coupling calculation, as shown in Figure 13. 


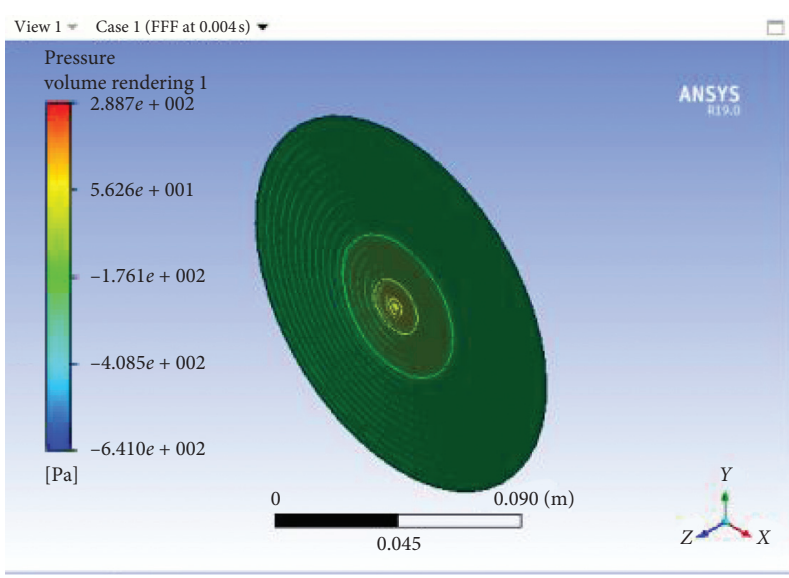

(a)

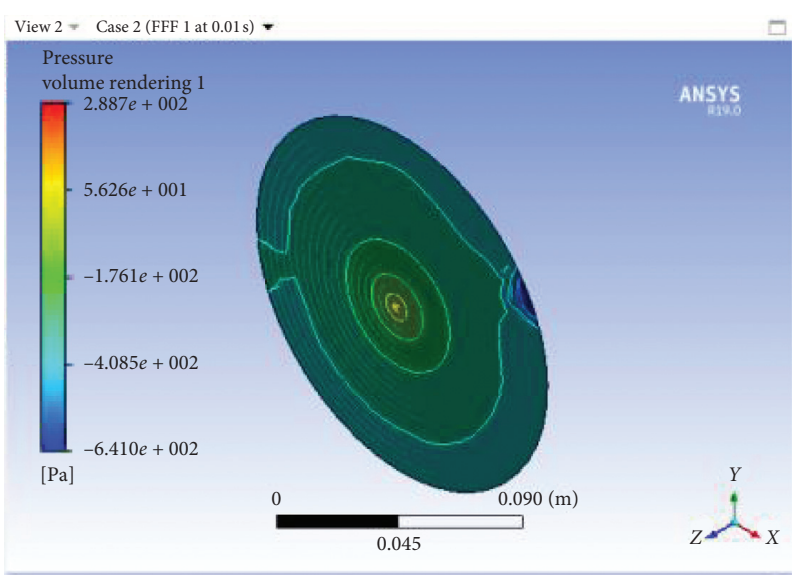

(b)

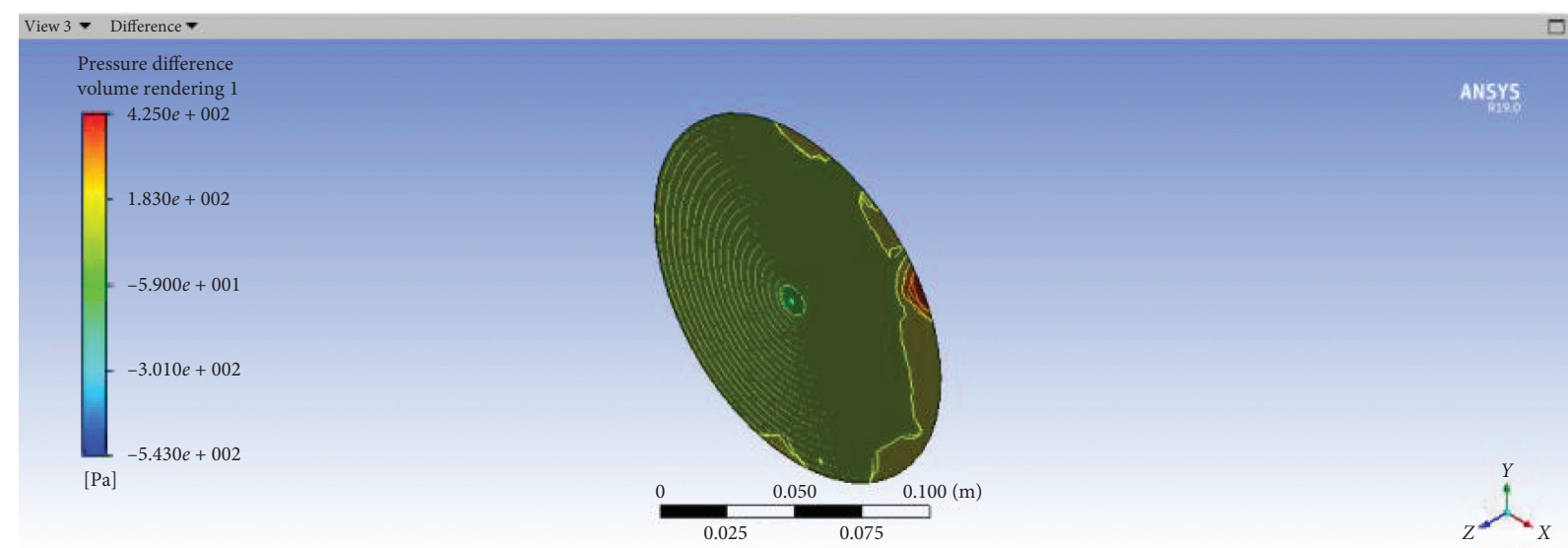

(c)

Figure 13: Hydrodynamic pressure at different times.

3.4.1. Distribution of Fluid Pressure along the Crack Depth. Figure 14 shows the distribution of fluid pressure along the crack depth. As can be seen from the figure, the smaller the distance from the crack front was, the greater the water pressure was. The maximum water pressure in the crack was not at the front of the crack, but near the front of the crack. This may be attributed to the fact that the water pressure in the crack is related to the penetration of water and water cannot penetrate into the front of the crack.

\subsubsection{Effect of Bubble Radius on Hydrodynamic Pressure.} Figure 15 shows the effect of the bubble radius on the hydrodynamic pressure. The crack radius is an important factor affecting crack water pressure. Due to the fact that the tire load was regarded as a square loading area with a side length of $200 \mathrm{~mm}$, the bubble radius ranged from 50 to $100 \mathrm{~mm}$ to ensure that loading was applied in the whole range of water-bearing cracks. As can be seen from the figure, when the driving speed and crack height were kept constant, the maximum hydrodynamic pressure increased with the increase of crack radius. When the crack radius reached a certain value, the water pressure might cause the crack to propagate.

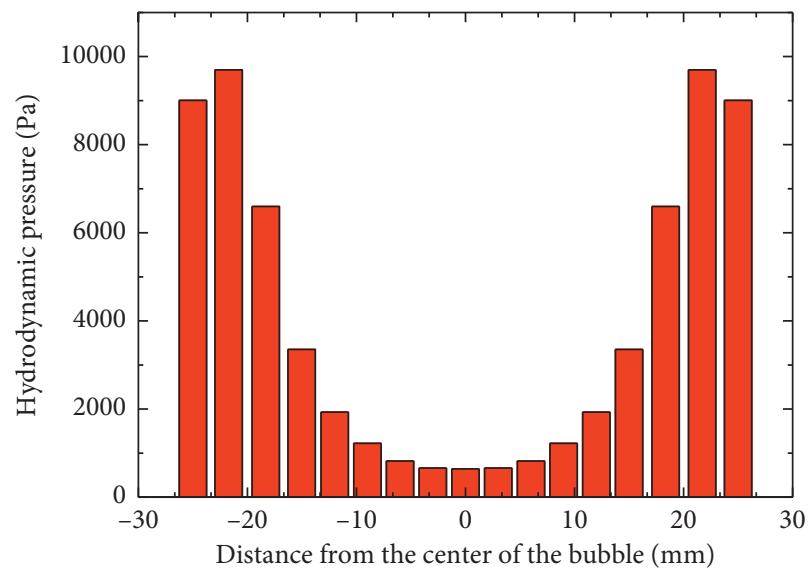

FIgURE 14: Fluid pressure distribution along the crack depth.

3.4.3. Effect of Bubble Height on Hydrodynamic Pressure. Bubble height is another important factor affecting hydrodynamic pressure, and its effect is shown in Figure 16. When the crack height increased from $1 \mathrm{~mm}$ to $2 \mathrm{~mm}$ and $3 \mathrm{~mm}$, the maximum hydrodynamic pressure decreased from $6789 \mathrm{~Pa}$ to $4922 \mathrm{~Pa}$ and $3557 \mathrm{~Pa}$. Thus, with the increase of 


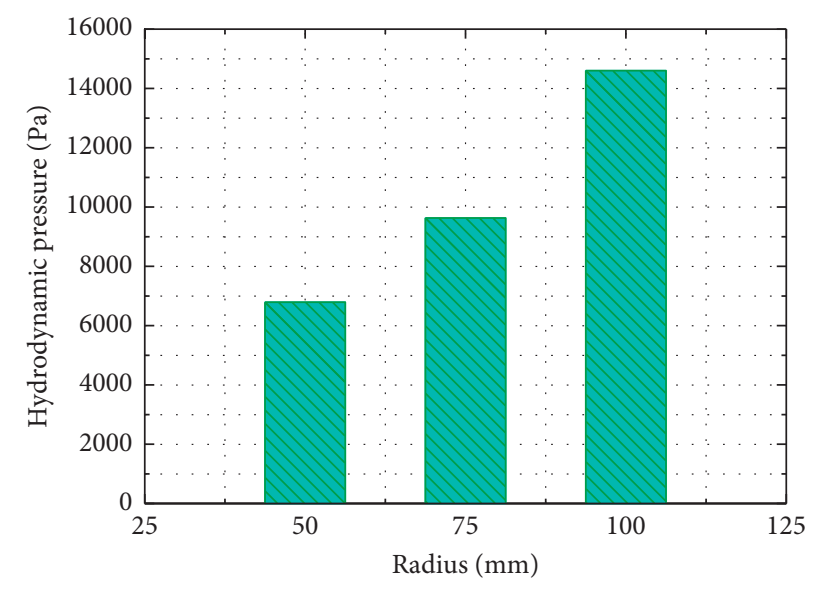

Figure 15: Effect of bubble radius on hydrodynamic pressure.

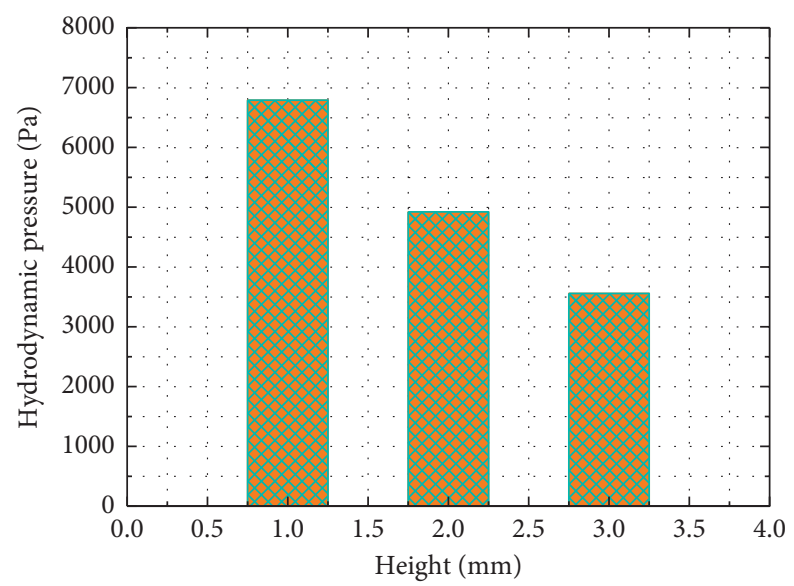

Figure 16: Effect of bubble height on hydrodynamic pressure.

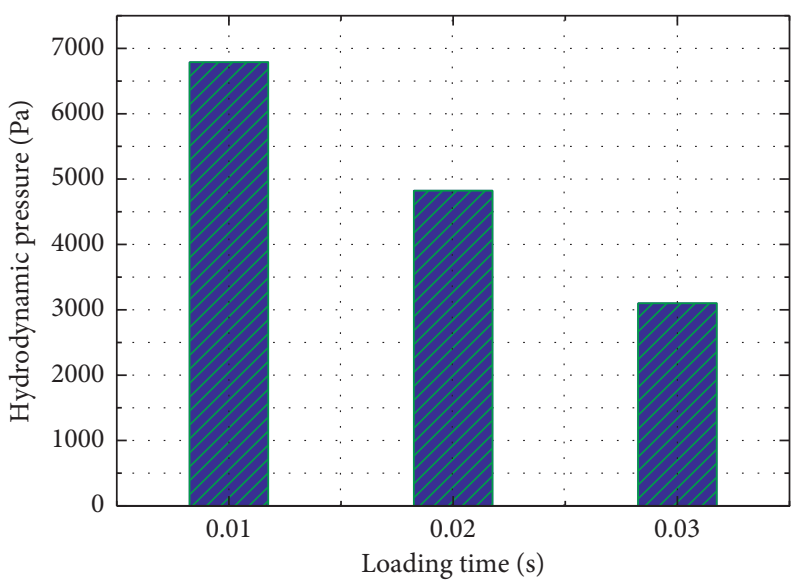

FIGURE 17: Effect of loading time on hydrodynamic pressure.

crack height, the hydrodynamic pressure in the crack decreased gradually.

The influences of crack morphology including crack radius and height may be related to the arch effect produced by the pavement layer. Owing to the existence of interfacial cracks, the pavement layer can be regarded as an arch bridge for water in the crack, which can disperse and transfer loading and further influence mechanical responses such as hydrodynamic pressure. 


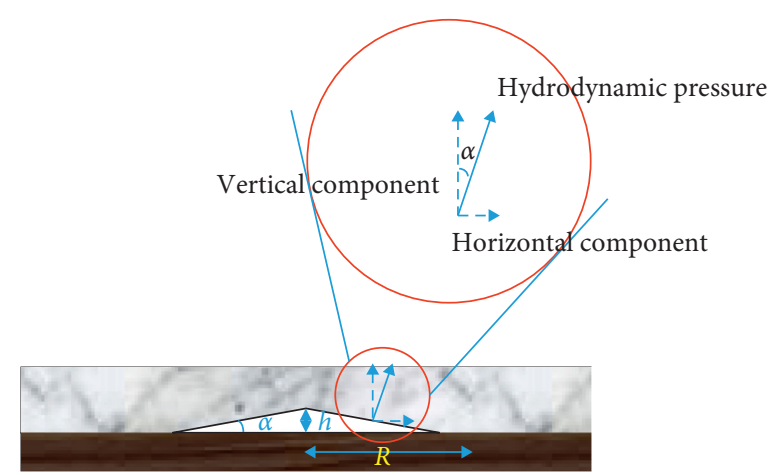

FIgURE 18: Diagram of hydrodynamic pressure component at the interface.

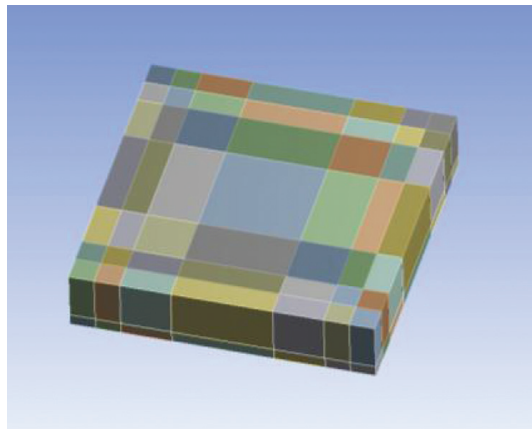

(a)

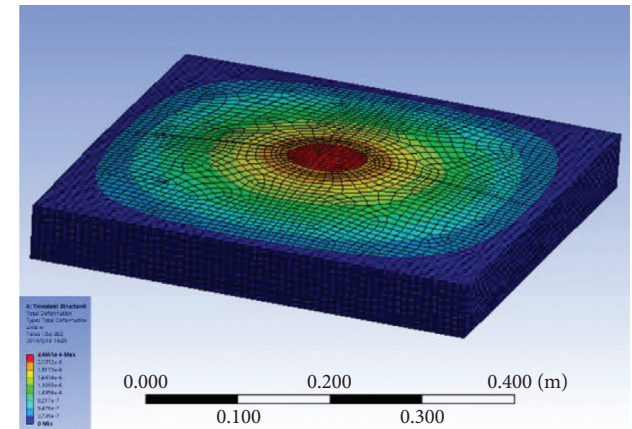

(b)

Figure 19: Crack propagation model and simulation results. (a) Model. (b) Total deformation.
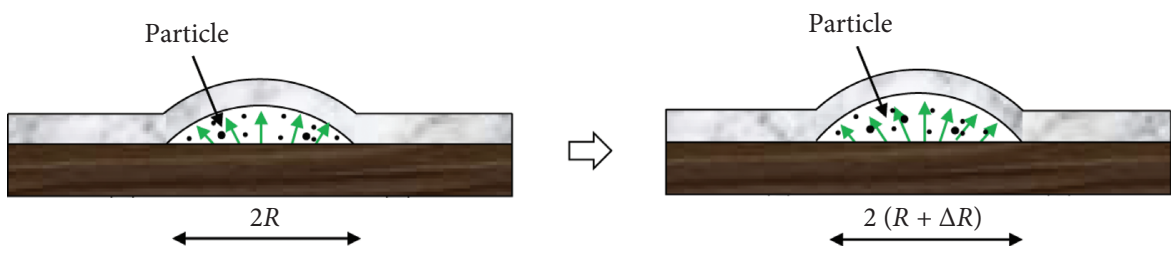

FIGURE 20: Interfacial crack propagation mechanism.

3.4.4. Effect of Loading Time on Hydrodynamic Pressure. Loading time is related to driving speed. The faster the driving speed is, the shorter the loading time is. It can be seen from Figure 17 that the hydrodynamic pressure in the crack increased with the increase in the driving speed. The larger the driving speed is, the more obvious the impact effect is.

3.5. Crack Propagation under the Coupling Action of Traffic Load and Water. The hydrodynamic pressure generated in the water-bearing interfacial crack plays an important role in promoting the propagation of the interfacial crack. The hydrodynamic pressure is perpendicular to the surface of the crack. For the interfacial crack, the crack height is usually small, and Mode I is the main fracture mode. But when the crack height cannot be ignored compared with its radius, the
Mode II fracture should also be taken into account, as shown in Figure 18.

Based on the calculation results of the hydrodynamic pressure, the energy release rate at the crack front under the coupling of load and water can be calculated. By comparing the fracture toughness obtained from the fracture test, the crack propagation can be judged. A three-dimensional finite element model was established to evaluate the fracture properties under loading and hydrodynamic water, as shown in Figure 19.

The calculation results showed that the energy release rate of Mode I was $9.2537 \mathrm{~J} / \mathrm{m}^{2}$ and that of Mode II was $4.5049 \mathrm{~J} / \mathrm{m}^{2}$ under the condition of maximum hydrodynamic pressure. It can be seen that the fracturing effect produced by the hydrodynamic pressure of the interfacial water-bearing crack is far less than the fracture toughness of the interface, which indicates that the selected adhesive 
can make the interface possess good fracture characteristics and ensure the interfacial cracks do not propagate under the load. From the perspective of paving material, the cementitious composites have large stiffness and can effectively disperse wheel loads (including impact loads), so the deformation of cementitious pavement is significantly less than that of asphalt pavement. This is also one of the advantages of cement-based materials to be used as steel deck pavement.

Although hydrodynamic pressure can hardly destroy the interface at one time, it can cause erosion fatigue damage to the interface. Under the action of scouring, the cementitious composite may break and produce particles. The water in the interface crack carrying concrete particles further aggravates the erosion of the interface, as shown in Figure 20. The interfacial crack may eventually lead to a large area of debonding between the pavement layer and the steel plate under the cumulative action of traffic load and water. Therefore, it is necessary to repair the interface crack in a timely manner.

\section{Conclusions}

In this study, the fracture characteristics of the wet-bonding interface of steel bridge deck pavement were studied. Modes I and II fracture toughness was tested with DCB and 4ENF specimens, respectively. Based on VCCT, the critical energy release rate and the uneven distribution of energy release rate at the crack front were analyzed. A fracture criterion for mixed fracture was established based on the blister test. A three-dimensional fluid-solid coupling analysis model was established to study the influence of various factors on the hydrodynamic pressure in the crack, and the influence of hydrodynamic pressure on the interfacial crack growth was also analyzed. Based on the obtained results, the following conclusions can be drawn:

(1) The energy release rates at the crack front of DCB and $4 \mathrm{ENF}$ specimens show obvious nonuniform distribution characteristics. Contrary to the DCB specimens, the energy release rates of $4 \mathrm{ENF}$ specimens are small in the middle and large on both sides. In addition, the fracture toughness of Mode II is obviously larger than that of Mode I.

(2) The comparison of the fracture parameters obtained by blister test with those obtained by DCB and 4ENF shows that $G_{\mathrm{I}} / G_{\mathrm{Ic}}+G_{\mathrm{II}} / G_{\mathrm{II}}$ is close to 1 , which indicates that the mixed fracture is in good agreement with the linear fracture criterion.

(3) The fracture effect produced by the hydrodynamic pressure of the interfacial water-bearing crack is far less than the fracture toughness of the interface, which indicates that the selected bonding material can make the interface have good fracture characteristics and ensure the interfacial cracks do not propagate under load.

(4) The hydrodynamic pressure can hardly destroy the interface at one time, but it can cause erosion fatigue damage of the interface. Under the action of scouring, the water in the interface crack carrying concrete particles further aggravates the erosion of the interface.

\section{Data Availability}

The data used to support the findings of this study are available from the corresponding author upon request.

\section{Conflicts of Interest}

The authors declare that there are no conflicts of interest.

\section{Acknowledgments}

The authors gratefully acknowledge the support of those who provided their generous help during the writing of this paper.

\section{References}

[1] J. Murakoshi, N. Yanadori, and H. Ishii, "Research on steel fiber reinforced concrete pavement on orthotropic steel deck," in Proceedings of the 2nd International Orthotropic Bridge Conference, Sacramento, CA, USA, August 2008.

[2] R. Walter, J. F. Olesen, H. Stang, and T. Vejrum, "Analysis of an orthotropic deck stiffened with a cement-based overlay," Journal of Bridge Engineering, vol. 12, no. 3, pp. 350-363, 2007.

[3] J. Hulatt, L. Hollaway, and A. Thorne, "Short term testing of hybrid $\mathrm{t}$ beam made of new prepreg material," Journal of Composites for Construction, vol. 7, no. 2, pp. 135-144, 2003.

[4] X. Shao, D. Yi, Z. Huang, H. Zhao, B. Chen, and M. Liu, "Basic performance of the composite deck system composed of orthotropic steel deck and ultrathin RPC layer," Journal of Bridge Engineering, vol. 18, no. 5, pp. 417-428, 2013.

[5] L. Bizindavyi and K. W. Neale, "Transfer lengths and bond strengths for composites bonded to concrete," Journal of Composites for Construction, vol. 3, no. 4, pp. 153-160, 1999.

[6] K. Nakaba, T. Kanakubo, T. Furuta, and H. Yoshizawa, "Bond behavior between fiber-reinforced polymer laminates and concrete," Aci Structural Journal, vol. 98, no. 3, pp. 359-367, 2001.

[7] L. Li, Y. Shao, and Z. Wu, "Durability of wet bond of hybrid laminates to cast-in-place concrete," Journal of Composites for Construction, vol. 14, no. 2, pp. 209-216, 2010.

[8] J. Xu, Interface Mechanism, Science Press, Beijing, China, 2006.

[9] J. G. Williams, "On the calculation of energy release rates for cracked laminates," International Journal of Fracture, vol. 36, no. 2, pp. 101-119, 1988.

[10] Z. Suo, "Delamination specimens for orthotropic materials," Journal of Applied Mechanics, vol. 57, no. 3, pp. 627-634, 1990.

[11] J. Wang and P. Qiao, "Interface crack between two shear deformable elastic layers," Journal of the Mechanics and Physics of Solids, vol. 52, no. 4, pp. 891-905, 2004.

[12] P. Qiao and J. Wang, "Mechanics and fracture of crack tip deformable bi-material interface," International Journal of Solids and Structures, vol. 41, no. 26, pp. 7423-7444, 2004.

[13] E. J. Rippling, S. Mostovoy, and R. L. Patrick, "Measuring fracture toughness of adhesive joints," Materials Research and Standards, vol. 4, no. 3, pp. 129-134, 1964. 
[14] D. J. Wikins, J. R. Eisenmann, and R. A. Camin, "Characterizing delamination growth in graphite-epoxy," Damage in Composite Materials, vol. 775, pp. 168-183, 1982.

[15] Q. D. Yang, M. D. Thouless, and S. M. Ward, "Elastic-plastic mode-II fracture of adhesive joints," International Journal of Solids and Structures, vol. 38, no. 18, pp. 3251-3262, 2001.

[16] R. H. Martin and B. D. Davidson, "Mode II fracture toughness evaluation using four point bend, end notched flexure test," Plastics, Rubber and Composites, vol. 28, no. 8, pp. 401-406, 1999.

[17] C. Hwu, C. J. Kao, and L. E. Chang, "Delamination fracture criteria for composite laminates," Journal of Composite Materials, vol. 29, no. 15, pp. 1962-1987, 1995.

[18] R. Rikards, F. G. Buchholz, H. Wang et al., "Investigation of mixed mode I/II interlinear fracture toughness of laminated composites by using a CTS type specimen," Engineering Fracture Mechanics, vol. 61, no. 3-4, pp. 325-342, 1998.

[19] J. D. Whiccomb, "Analysis of instability-related growth of a through-width delamination," Technical Report, National Aeronautics and Space Administration, Langley Research Center, Hampton, VA, USA, 1984.

[20] J. W. Gillespie, L. Carlsson, R. B. Pipes, R. Rothschilds, B. Trethewey, and A. Smiley, "Delamination growth in composite materials," Contractor Report, NASA, Hampton, VA, USA, 1986.

[21] E. M. Wu and J. R. C. Rcuter, "Crack extension in fiberglass reinforced plastics," T and AM Report, Illinois University, Champaign, IL, USA, 1965.

[22] J. R. Reeder, An Evaluation of Mixed-Mode Delamination Failure Criteria, Createspace Independent Publishing Platform, Scotts Valley, CA, USA, 1992.

[23] H. T. Hahn and T. Johannesson, "A correlation between fracture energy and fracture morphology in mixed-mode fracture of composites," Mechanical Behaviour of Materials, vol. 4, no. 1, pp. 431-438, 1984.

[24] E. F. Rybicki and M. F. Kanninen, "A finite element calculation of stress intensity factors by a modified crack closure integral," Engineering Fracture Mechanics, vol. 9, no. 4, pp. 931-938, 1977.

[25] K. N. Shivakumar, P. W. Tan, and J. C. Newman, "A virtual crack-closure technique for calculating stress intensity factors for cracked three dimensional bodies," International Journal of Fracture, vol. 36, no. 3, pp. 43-50, 1988.

[26] J. Wang, Q. Dai, S. Guo, and R. Si, "Mechanical and durability performance evaluation of crumb rubber-modified epoxy polymer concrete overlays," Construction and Building Materials, vol. 203, pp. 469-480, 2019.

[27] H. Dannenberg, "Measurement of adhesion by a blister method," Journal of Applied Polymer Science, vol. 5, no. 14, pp. 125-134, 1961. 